\title{
París: Roteiro Castelao. Diario 1921
}

\author{
Paris: the Castelao Route. Diario 1921 \\ LUZ LÓPEZ CORREA \\ IES Illa de Tambo, Marín. Pontevedra. \\ mlcorrea@edu.xunta.es \\ Recibido: marzo 2021. Aceptado: abril 2021
}

\begin{abstract}
Resumo: A.D.R. Castelao (1886-1950) é un dos grandes referentes da cultura e arte galega, así como da política. Neste artigo propoñemos un percorrido polo París dos anos vinte seguindo as anotacións do seu Diario 1921. Acto seguido, unha tarefa de identificación onde trataremos de relacionar as súas vivencias na devandita cidade coa súa obra posterior.
\end{abstract}

Palabras chave: Castelao, Diario 1921, influencias, literatura galega, París anos 20, pintura

\begin{abstract}
A.D.R. Castelao is one of the great referents of Galician culture and art, as well as of politics. In this article we propose a journey through the Paris of the twenties following the notes of this Diary 1921. Then, an identification task where we will try to relate his experiences in that city with his later work.
\end{abstract}

Key words: Castelao, Diario 1921, influences, Galician literature, Paris in the 1920s, painting

\section{INTRODUCIÓN}

Escribe o mestre e insigne Otero Pedrayo, na homenaxe e lembranza de Castelao: «Prefiro agardar a súa chegada. Ou a carta de cousas ateigadas, finas, novas. A carta de París que il amou como poucos» (Otero Pedrayo 1975:3).

París está presente ao longo de toda a súa vida, a primeira viaxe é a do 1921, pero volverá no 1927 co seu amigo Iglesias Vilarelle, musicólogo-compositor e psicólogo, despois de ir a Bordeos á consulta do Dr. Lagrange, famoso oftálmologo. No 1935 vai coa súa dona a París e Países Baixos. Hai outra viaxe súa a Francia da que temos escasos testemuños, soamente, algunha carta a amigos, como Otero Pedrayo. Fai varias veces escala na cidade: de regreso de 
Alemaña neste 1921, na ida e volta de Bretaña no $1929^{1}$ e ao vir de Moscova no 1938. Anos máis tarde, en agosto do 1946 instálase aquí, como ministro no goberno republicano do exilio. Nesta ocasión vive un tempo na rúa Lafayette, 60, no hotel Modern Lafayette, cerca do Museo Grevin.

A primeira estancia en París, a que nos referimos, abarca desde finais de xaneiro a mediados de xuño do 1921. Nestes meses visita museos e exposicións de pintura; asiste a concertos, espectáculos teatrais, relatorios e toma notas no seu Diario; escribe cartas á súa familia e compra libros ${ }^{2}$ para estudar e comprender as novas correntes artísticas. Así, pois, as impresións que escribe no seu Diario1921 son froito da observación das exposicións e museos e tamén das lecturas de libros, catálogos, prensa, etc. Así, aínda que en determinados momentos se amose decepcionado coa cidade: «Non, ho. París non entrará en min nin eu nil» (Castelao 1977:65) ao remate da súa estancia na cidade da Luz, afirma: «Deprendín moito en París sen perder unha migalla tan siquera das miñas ideas. O esquelete do meu arte ganará moito con iste viaxe» (Castelao 1977:168).

Este artigo ten como obxectivos: elaborar unha ruta cultural no París dos anos 20 seguindo as exposicións e os seus paseos pola cidade, plasmados no seu Diario 1921. Incidir no valor desta obra, un auténtico tesouro artístico, tanto pola beleza da súa presentación, como polos inxentes e valiosos datos que nos proporciona sobre o panorama cultural da Europa dos anos vinte. Neste punto, hai que ter en conta, que é unha obra anterior ou, cando menos, contemporánea dos grandes estudos sobre as vangardas a nivel peninsular, o que, sen dúbida, acrecenta o seu valor. Xa, como última encomenda, lonxe de explicacións científicas sobre as obras que se citarán do autor, o que pretendemos é desvelar aspectos, influencias, sutilezas e anécdotas desta viaxe a París, que máis tarde influirán na súa obra pictórica e literaria. Outro fío que seguimos foron as lecturas e libros ${ }^{3}$, algúns deles mercados nesta viaxe, para establecer relacións co que escribe. Somos conscientes de que, ás veces, as analoxías descritas son tenues, difíciles de imaxinar e corroborar. Quizais estas palabras súas dan conta destes matices (Castelao 1977: 145):

Eu quero pintar unha carabela e se non a roubo de calquera dibuxo teño que inventala; pero estando en París logo se vai ó Museo de Marina do Louvre e alí vexo carabelas cantas queira, reducidas iso sí, pero que poden deixarme ver un aspeuto que eu non podería imaxinar ainda sabendo ben como eran.

1 Á volta da Bretaña, alóxase no hotel de la Loire, 20-22, rúa Sommerard.

2 Actualmente estes libros, así como, algunhas cartas, pertenzas persoais, o manuscrito do Diario 1921 e doutras obras súas consérvanse no fondo Castelao da Biblioteca do Museo de Pontevedra. En relación con este tema, a obra de: Redondo Abal, F. X. (2010): Proceso a unha biblioteca. A persecución de Castelao a través da incautación da súa biblioteca, Santiago de Compostela. Edicións Laiovento. Este museo alberga, tamén a meirande parte da súa obra pictórica.

${ }^{3}$ O meu agradecemento ao, entón, director do Museo de Pontevedra, Valle Pérez, ao director do Gabinete Didáctico, José Manuel Castaño, e ao persoal da biblioteca do devandito museo que me deron todo tipo de facilidades para a consulta do material bibliográfico do Fondo Castelao entre os anos 2012-2015.Agradecemento que fago extensíbel a: Salvador Castro, Manuel González e Pedro e Xiana Toranzo. 


\section{II.- CASTELAO E PARÍS, 1921}

Segundo nos conta Filgueira Valverde no limiar do Diario 1921, Castelao recibe unha bolsa de estudos (R.O. do 30/9/1920) da Junta para la Ampliación de Estudios, daquela presidida por Ramón y Cajal, para levar a cabo unha viaxe de estudos por Francia, Alemaña, Bélxica e Inglaterra. Esta viaxe abarca case todo o 1921. Como estaba obrigado a presentar memorias mensuais, Castelao escribe un diario de viaxe. Este caderno permaneceu inédito até o 1977, agás os artigos que publicou ao longo de 1922-23 na revista Nós. O Diario está dividido en tres partes: En París, Nos Países Baixos, Na Alemaña. "Leva dediante unha nota de humor: o nome de Castelao en xaponés, co valor simbólico das letras. Cada unha das tres divisións vai precedida por un autorretrato" (Filgueira Valverde 1977: 11-12).

As rúas do Barrio Latino, que se estende aos pés do outeiro de Santa Xenoveva, patroa de París, gardan os ronseis das numerosas singraduras de homes e mulleres que soñaron e intentaron construír un mundo mellor. Malia que hoxe moitas librarías e cafés de faladoiros foron substituídos por tendas de moda e restaurantes, o peso da historia é inevitábel. O Barrio Latino - chamado así, por ser o latín a lingua oficial do ensino ata a Revolución Francesa - identificado coa vida intelectual, artística e bohemia é tamén o barrio da Universidade, das Grandes Escolas e dos Colexios máis prestixiosos.

Neste frío día de inverno do 1921, o noso viaxeiro chega á Gàre d’Orleans (actualmente Museo d'Orsay) e vén dereito ao Barrio Latino, Hôtel Saint Michael, por consello do seu amigo pontevedrés, Manolo Quiroga, naquel entón, un dos mellores violinistas do mundo. Logo múdase ao Hôtel des Termes, rúa Saint Jacques. Esta rúa, unha das máis antigas de París, é o anaco de Europa máis vinculado historicamente a Galicia. A carón da igrexa Saint-Jacques e despois do Museo de Cluny xuntábanse os milleiros de peregrinos que abriron o Camiño Francés a Compostela. Moito tempo antes da expansión do cristianismo en Europa, ao parecer, existía unha ruta iniciática que se dirixía a Fisterra, ao lugar onde empeza o Mar dos Mortos do que ninguén volvía. No discurso do día de Galicia en Bos Aires, en xullo de 1941, Castelao fai alusión a esta ruta (Castelao 2000a: 453):

Se dice que las primeras ansias de conocimiento incitaban a caminar a los hombres y que una tribu de alma viajera, salida de Oriente, empezó a caminar siguiendo la ruta del sol, y que, andando, andando, llegó al fin de la tierra, es decir, al Finisterre gallego, y allí se quedó, pasmada de asombro ante la inmensidad y el infinito.

A Tour Saint-Jacques (na marxe dereita do Sena, seguindo a rúa) e a figura de Saint-Iago son lembrados noutro emocionante discurso, o 25 de xullo de 1948, en Bos Aires, titulado: A significación espritoal do día de Galiza: «Europa representou ao Apóstolo Sant- Iago a semellanza dos seus pelegríns: con esclavina e chapeau cobertos de cunchas vieiras(...) tal como se ve no cume da torre Saint Jacques de París» (Castelao 2000a: 554). 
Hoxe podemos deleitarnos con este impresionante campanario gótico-flamíxero da Tour Saint- Jacques e camiñar polas rúas do barrio Châtelet e Les Halles imaxinando a atmosfera do pasado: o grande mercado de París, onde a venda de todo tipo de produtos convivía con mimos, xograres, esmoleiros, tolleitos, falsos eivados e vagabundos. Vida e morte mesturábanse nestas rúas algareiras, infames, fedorentas a carón dos ecos dos poderosos carniceiros e dos laios dos presos do cárcere de Grand Châtelet. E postos a imaxinar sentiremos os pasos dos peregrinos cara a Compostela e as idas e vidas de Rañolas, un dos protagonistas, da súa novela Os dous de sempre (1934). Neste mesmo barrio no Centro Pompidou, Museo de Arte Moderna, reviviremos as súas emocións diante das obras de Frantisek Kupka ${ }^{4}$ (Castelao 1977: 153):

\begin{abstract}
Estiven na exposición de François Kupka. Presenta moitos cadros: algúns en branco e negro, os demáis a toda côr. (...) De todas cantas eisposicións das novas artes vin dende que estou eiquí ista é a que máis me intresou (...) Os títulos dos cadros de Kupka son moi intresantes: "Bleus et rouges modulés", "La contradanse", "Ideación (couleurs majorées)", "Verticales (sonores par association)", etc.,etc.
\end{abstract}

Moi cerca do seu hotel, no Barrio Latino, vive Gertrude Stein, intelectual epicentro dunha cultura de alteridade e transgresión, mecenas de pintores e escritores da época. Outras moitas artistas e dinamizadoras das artes: Eugenia Huici Errazuriz, Anaïs Nin, Natalie Barney, Adrienne Monnier, Dyuna Barnes, Edith Wharton, Janet Flanner, Sylvia Beach... marcaron os alicerces dunha cultura alternativa que facilitaría o nacemento do feminismo na segunda metade do s. XX. Tan só uns meses máis tarde da estancia de Castelao neste barrio, Sylvia Beach, dona da libraría Shakespeare \&Co, creada en novembro de 1919, no número 8, da rúa Dupuytren e ampliada no 1921, na rúa L’Odeon, publica o Ulises de James Joyce (1882-1941). Castelao non cita esta libraría, aínda que nos seus paseos cara ao Museo de Luxemburgo, posibelmente, reparase nela. Fronte a esta, na citada rúa L'Odeon, estaba «La maison des amis du livre», especializada en libros franceses, fundada por Adrienne Monnier, e frecuentada por toda a vangarda literaria francesa: Breton, Apollinaire, Aragon, Valery, Cocteau, etc.

Todos estes escenarios e personaxes serán retratados por Ernest Hemingway no seu coñecido libro París era una fiesta (1964). Ao longo destas páxinas descubrimos o ritmo cotiá do barrio e os estados de ánimo do autor marcados pola pobreza e pola beleza. A emoción ante a beleza e asemade as dificultades económicas do noso viaxeiro (1977:46) son semellantes ás sentidas polo escritor americano (Hemingway 1994:75):

Y siempre podía uno entrar en el museo del Luxemburgo, y los cuadros se afilaban y aclaraban y se volvían más hermosos cuando uno los miraba con el

${ }^{4}$ Para contemplar as obras deste artista seguir esta ligazón: https://www.centrepompidou.fr/ cpv/resource/c9jjoqA/ro4Gn4o. 
vientre vacío y con la ligereza que da el hambre. Teniendo hambre, llegué a entender mucho mejor a Cézanne y su modo de componer los paisajes.

Castelao fai seu este entrañable barrio; pasea as súas rúas, visita os seus monumentos, os museos, os xardíns, merca libros e estampas e asiste a conferencias na Sorbonne ou no College de France. Nos cafés escribe, debuxa e pensa. Son varios os debuxos que pinta no 1921 relacionados coa temática dos cafés: Muller sentada con copa, Faciana de home con pipa, Dous homes, Parella nun bar, Muller nun bar, ${ }^{5}$ posiblemente, inspirados nestes emblemáticos locais: Café de Flore, Le Procope, Le Closerie des Liles ou Les Deux Magots, a onde acode Risco, en 1931, tal como refire na súa obra Mitteleuropa: «Fun tomar café nos Deux Magots. Case todos os que había alí eran estranxeiros» Risco (1931:35). Hoxe podemos visitar estes cafés históricos e tratar de achar a maxia do pasado que endexamais volverá, pero evocaremos as reflexións do noso artista sobre as artes, advertindo que no pouso do café se debuxa unha liña en espiral símbolo do decorrer do tempo. E para que o peso do existencialismo non nos abafe demasiado, gorentarémonos co sabor da madalena proustiá, que nos anticipará a posíbel coincidencia de Castelao con Marcel Proust (18711922) nunha tarde do mes de maio.

Quizá agora sexa o momento de volver ao cuarto do hotel e repasar o seu percorrido polos museos: "Pasei o día no Louvre e vin tantas cousas que teño a testa chea de papas" Castelao(1977:30). As súas afirmacións corroboran a súa entrega á arte deste grande museo, ao igual que o grande artista, Alberto Giacometti (1901-1966) quen, publicamente, recoñecía que tiña todo o Louvre na cabeza, sala por sala. Castelao céntrase, sobre todo, nas obras dos primitivos flamengos, holandeses e alemáns e vai inspirarse, maiormente, na obra de Brueghel (1525-1569) á hora de pintar a serie Os cegos, meus irmáns. Descobre o seu cadro A parábola dos cegos (1546) neste museo e queda impresionado con esta obra, sobre a que reflexiona ao longo de toda a viaxe (Castelao 1977:71):

En troques, velahí está ise cadro de Brueghel. ¿Poderían Boccioni, Carrá, Russolo, Bala, Severini, Picasso, Braque, Derain, Metzinger, Delaunay, Valensi, Russel, Wright, Vlaminck, etc., todos iles xuntos, faguer unha obra de arte coma isa?

Aos cegos dedicará unha boa parte da súa obra gráfica, posibelmente, sensibilizado pola súa propia cegueira ou polo afán de retratar o mundo, desde a perspectiva da dor e do sufrimento. No seu cadro A familia do cego (1940) achamos certa semellanza cunha escultura de Cordonnier (1848-1930) titulada Sur le pavé (1903) que contempla no Museo de Luxemburgo (Castelao 1977: 57):

5 A obra pictórica de Castelao conservada, maiormente, no Museo de Pontevedra pódese visualizar nesta ligazón: http://www.museo.depo.gal/coleccion/catalogo.castelao/ ga.03110000.html. Tamén: https://www.realacademiabellasartessanfernando.com/assets/docs/pdf/ Cat\%C3\%A1logo\%20Castelao\%20grafista.pdf. 
Eu penso que a escultura debía de renovarse esquecendo o desnudo ou falseándoo para sere un elemento da arquiteutura. Aquilas duas figuras vestidas, de Roger Bloche tituladas "Le froid", que mesmamente teñen frío, e aquila cega coa filla, tamén vestida, de Cordonnier, titulada Sur le pavé demostran a razón que eu teño.

Imaxinando a nosa visita ao Louvre contemplaremos A Vitoria de Samotracia, unha das obras máis admiradas polo noso ilustre viaxeiro: « (...) cada día que a vexo góstame máis. Está na proa dun barco e mesmamente parece que o barco andaría soio con ela, sen velas, nen motor nen nada. Tal forza ten.» (Castelao 1977:38). Parecida admiración comparte Lion Feuchtwanger na novela Exilio onde a retrata coma o símbolo de esperanza fronte á barbarie nazi. (Feuchtwanger 1966:1371-1380).

Seguiremos a visita coa pintura flamenga: Memling, Brueghel $o$ vello, Jan van Eyck, Frans Hals, Patinir, Vermeer, Rembrandt... e o cadro L'homme au verre du vin: «considerado como a xoia da pintura antiga francesa (ano1456) e polo visto é do noso Nuno Gonçalves» (Castelao 1977: 31).

A ilustración Home muxindo unha vaca deste Diario 1921 e a lámina Así quixeron sempre que fose a nosa Terra (1922-24) están inspiradas nunha escultura que contempla nas inmediacións do museo: «Perto do Louvre hai unha escultura, "Les fils de Caín" e nela vin a lira que está copiada ahí enriba, feita coa calivera dun boi» (Castelao 1977: 82).

Enfiando unha nova mañá por esta cidade, nacida nunha ínsua e abrazada a un río, camiñamos a carón do Sena «coas súas augas arremoiñadas que fan rezar polos que se afogaron nelas» (Castelao 1977:30). E contemplando este río, Adrián Solovio, o protagonista de Arredor de Si, de Otero Pedrayo, pescuda o ritmo do latexar humano e cavila nas forzas cósmicas que rexen a lei dos tempos: «Este Sena, licor de suicidas, espello de pálidos fracasados» (Otero 1926:12).

Hoxe ollamos as súas augas na procura do segredo das nosas vidas que, contra o racionalismo francés, se tecen, ás veces, con fíos de azares e de encontros. Mais só nos deteremos ao lado do Sena para mirar as estampas dos bouquinistes, porque o noso viaxeiro descobre Notre-Dame (actualmente en reconstrución) adiviñándoa entre a brétema e sente un abalo de emoción. Nós, imaxinando a escena, intentamos deixarnos ir, ceibes de todas as engrenaxes da existencia. Amor á arte, á beleza que tan ben nos transmite o noso artista. As esculturas desta catedral serán obxecto de estudo, sobre todo, as gárgolas que debuxa no seu Diario: «A que máis me impresiona é ise demo dos cornos coa lingoa de fora mocándose da cibdade que fita dende aquelas outuras. Tamén é xenial o paxaro cuberto cun manto que dibuxei o día 5» (Castelao 1977: 46).

Dentro fica abraiado diante de tanta beleza: «A luz deste día morno deixaba ollar os ventanals tan fermosos que na vida ollei tanta regalía dos ollos» (1977: 29). Por fin, atopa o acougo necesario para mitigar a súa morriña. Abandónase ao pracer da suspensión do tempo, ás fabulacións que o levan a percorrer os camiños das emocións, libre de ataduras e de prexuízos: «Nun curruncho escoitei o órgao, que me fixo estremecer (...). Eu non agardaba aquilo e rompín a 
chorar coma se fose un neno (...). En Notre Dame eu síntome dino de sere home e choro.» (1977:55)

Albert Camus describe semellantes emocións de saudade e nostalxia na súa obra El revés y el derecho cando visita un claustro barroco en Praga (Camus 2009: 63):

Una vez, sin embargo, en un claustro barroco, en una de las puntas de la ciudad, la dulzura de la hora, las campanas que tañían despacio, unos racimos de palomas que brotaban de la antigua torre, y también algo así como un aroma a hierba y a anonadamiento hizo nacer en mí un silencio tan colmado de lágrimas que me puso al filo del alivio.

Despois de tanta señardade, un paseo pola praza Vert-Galant e unha visita a Sainte Chapelle darannos azos: «A capela de enriba mesmamente parece un farol dunha fermosura de côres que mete xenio» (Castelao 1977: 36).

Nunha mañá nova seguiremos as pegadas dos comunards e subiremos co noso viaxeiro a Montmartre. Nese máxico outeiro tomaremos o primeiro café, mentres os gatos de Steinlein (1859 - 1923) se espreguizan, nostálxicos dun tempo pretérito de arte e rebeldía, de compromiso e bohemia. No 73, rúa Caulaincourt, viviu este pintor. A súa pintura denuncia os males do capitalismo: miseria, inxustiza, paro. «O mundo non vai como debería de ir», sostiña este artista. Os aldeáns, obreiros, pobres, desequilibrados, os que loitan contra a miseria e os que viven nela son lembrados e homenaxeados na súa obra. Steinlein non cre na arte pola arte, senón no papel social da arte. Castelao cita este artista no seu Diario cando visita unha exposición en Alemaña: «Nunha casa que venden grabados vin cousas boas e moi intresantes coma procedimento de grabado. Eran litografías ó xeito de Steinlein (cousas de dôr e de miseria)» (Castelao 1977: 283).

Na biblioteca de Castelao consérvase unha lámina de Steinlein Le martyre de la Serbie, ademais, do libro La Guerre par Steinlein e a obra de F. L. Enmanuel Los dibujantes de Montmartre. Nesta última obra aparecen Steinlein e outros tantos creadores de Montmartre, que daquela frecuentaban Le Chat Noir, punto de reunión de pintores e bohemios, e famoso polo seu teatro incomparábel. Hai dous debuxos dela titulados: Ela tamén casou cun vello e Revolución que nos lembran algunhas imaxes de Castelao. Os dous artistas coinciden: a arte debe ter unha utilidade social, premisa relacionada co papel de propaganda política xogado polos debuxantes humoristas franceses e centroeuropeos durante a Primeira Guerra Mundial. A arte ao servizo dos seus ideais e da súa Terra, obxectivo materializado na obra pictórica e literaria do noso autor, especialmente, en $O s$ albums de Guerra e nos cartaces a prol do Estatuto de Autonomía do 1936.

Non deixaremos Montmartre, sen lembrar antes o Batteau- Lavoir, na praza Ravignan, onde Picasso pinta: Las señoritas de Avignon (1907). Moitos artistas frecuentan este luga, entre eles: Apollinaire, Utrillo, Marie de Laurencin e Suzanne Valadon. Actualmente na antiga vivenda de Utrillo e Suzanne Valadon, no número 12, rúa Cortot, está o museo de Montmartre. As dúas pintoras referidas, o mesmo que: Camille Claudel, Marie Cassat, Béatrice How, Berthe 
Morisot, Marie Bracquemond, entre outras, forman parte dunha nómina, que por mor do ambiente misóxino da época, non foron, debidamente, valoradas. No París dos anos vinte, o mundo da ciencia e da arte noméase en masculino. A muller ten máis valor coma modelo que coma pintora, polo tanto, as exposicións de autoría feminina son escasas. Por todo o dito, son importantes as alusións do noso autor sobre a valía de Beatrice How: «inglesa, moi ben, moi ben pintando ao óleo como se fose acuarela» (Castelao 1977: 121) e de Marie de Laurecin (Castelao 1977:96):

Ista artista é moi coñecida en Paris. Ten unha téinica que se repite sempre en todolos cadros(...). Os vellos teñen sempre unhas folicas e as liñas negras son sempre así: Pódese decir que o encanto distes cadros está nos ollos negros que veñen a sere coma un berro na brétema. A min gustoume moito.

Baixando pola rúa Blanche, chamada así pola súa cor, resultado da fariña transportada proveniente dos muíños de Montmartre, cara aos bulevares, atopamos o barrio denominado A Nova Atenas, onde residían moitos dos artistas a finais do s. XIX, hoxe lembrados a través das placas informativas. Célebre tamén polo cabaré Chat Noir e revista homóloga, ilustrada por Steinlein. Aquí visitaremos o Museo de Gustave Moreau (1826- 1898) e fabularemos diante das súas composicións oníricas e mitolóxicas. Este pintor, pertencente á corrente simbolista, inflúe notabelmente nos futuros surrealistas: Bretón, Max Ernst e Salvador Dalí. Na lámina «Esta dor non se cura con resiñación» do Álbum de Guerra, Galicia mártir (1937) achamos unha certa semellanza coa obra Pietà Ebauche. ${ }^{6}$ do devandito artista. En palabras do noso viaxeiro (Castelao 1977:153):

Estiven no Museo de Gustavo Moreau. Iste artista traballóu moito, moito, moito e penso que de poucos se pode xuntar unha tan grande coleución.(...) É un gran decadente que fixo moitas cousas boas. Tiña moita intelixencia e non se pode dubidar de que foi un bó artista.

Aínda nos quedará tempo para poder visitar outro dos emblemáticos museos da cidade, Museo Rodin, que debería chamarse: Claudel-Rodin, (actualmente o Museo Camille Claudel en Nogent-sur-Seine resarce, en parte, esta inxustiza). Camille Claudel foi coautora de importantes obras da autoría de Rodin (1840-1917), tales como: Os burgueses de Calais e A porta do inferno. O noso viaxeiro detense nunha das obras máis significativas, o Pensador ${ }^{7}$ (daquela estaba no Panteón): «Eu penso que non pensa senón que está desesperado (...) Neste París o penseur de Rodin poida que non goste ás xentes». (Castelao 1977:31). Sobre a estatua de Balzac amósase defraudado: «Teño que confesarme que a estatua de Balzac pareceume unha morea de merengue» (1977:102). As súas reflexións e xuízos coinciden moito coas de Rodolfo Dirks: «Cuando Rodin expuso su Balzac, en el salón de 1848, el público y la crítica

6 Pódese contemplar a obra a través deste ligazón: https://www.dessins-musee-moreau.fr/ selection/page_notice-ok.php?Ident=R\&myPos=1\&NoticeId=3005. (Consultado o 07/08/2020).

7 Ligazón: http://www.musee-rodin.fr/ 
fueron de la misma opinión que la sociedad: Rodin se equivocó; es un hombre de nieve» (1909:30).

Agora deixaremos profundando ao noso viaxeiro sobre a pegada das cousas e das horas e iremos cara ao Museo Cernuschi, ao lado do aristocrático parque Monceau. A súa visita coincide cunha exposición temporal sobre a arte chinesa: Les nouvelles expositions chinoises du musée Cernuchi. $\sigma^{a}$ exposition rêtrospective d'art chinois. janvier- mai, 1921. ${ }^{8}$ Algunhas imaxes deste museo ${ }^{9}$ son evocadas nos debuxos do Diario e noutras obras. Así, un tapiz chinés pode ser o elemento inspirador para pintar o seu cadro O Viático (Castelao 1977:144):

O tapiz está bordado en seda e ouro; nun fondo azul ultramar os arbres en côr de cera e dourado aparecen estilizados; hai un pino ademirabel; antre os albres aparecen en grupos, os letrados, sempre en côr de cera e dourado; hai un equilibrio perfeuto na composición, que non é tan enrabexada como son algunhas cousas chinas.

No seu Diario manifesta especial atención pola arte oriental chegando a dicir: «o arte chino e o seu fillo xaponés non teñen comparanza con ningún» (1977:135). Sinal desta admiración son as visitas ao Museo Guimet ${ }^{10}$, de arte asiática, do que toma moitas notas, sobre as que escribe e fai ilustracións no seu Diario: «No Museo Guimet pasei algunhas tardes dediante dos dibuxos e das estampas xaponesas» (1977:110).

Na súa biblioteca consérvase un folleto da Exposición de Estampas japonesas antiguas y modernas. Neste catálogo destaca a Escola Ukiyo-e que presenta composicións da vida cotiá e o uso de fondos negros. Obras de: Asahi, Asada, Fujita, Nomura, Utamaro, entre outros. O sintetismo, cores planas e a linealidade desta escola son características que admira. Así, pois, nos cadros Cons ou Devalando(1920-22) e Gaivotas ou Norte escuro (1920) vemos semellanzas no tratamento da escuma do mar coa obra de Hosukai Katsushika (1760-1849). Este pintor, un dos máis grandes paisaxistas xaponeses, é autor dunha serie de 36 gravados do Monte Fuji na xilografía titulada Sunshuu Ejiri (nome dun lugar). Segundo o profesor e académico, Fernández Rei, (2015: 573-574) o investigador, Asaka Takekazu, tradutor ao xaponés de Vento Mareiro, subliña a influencia deste artista nipón na composición da paisaxe, pintada por Castelao, na cuberta da $2^{\mathrm{a}}$ edición de Vento Mareiro (1922) de Cabanillas (1876-1959).

Volvemos a Occidente, à la recherche du temps perdu... (á procura do tempo perdido) e non deixa de sorprendernos a posible coincidencia do noso

8 ARDENNE DE TIZAC, Henry " 6 ' exposition rétrospective d'art chinois[Les nouvelles expositions chinoises du Musée Cernuschi]"in La Revue de l'art ancien et moderne, janvier- mai. 1921, tome 39, p.75-78.

http:// cernuschi.paris.fr/sites/default/files/les_expositions de 1911 à 1960 pdf.(Última consulta o 26 de maio de 2020)

9 Para consultar as obras deste museo: https://www.cernuschi.paris.fr/fr/node/1123. Última consulta o 5 de agosto de 2020).

$10 \mathrm{https}: / / \mathrm{www}$. guimet.fr/ 
viaxeiro na Exposición temporal de pintura holandesa, do museo Jeu de Paume con Marcel Proust ${ }^{11}$ (1871-1922). A sublime experiencia de Proust foi contada por Muñoz Molina no artigo La fiebre manuscrita (2013:14):

Un día de mayo de 1921, ya muy debilitado,fue al museo Jeu de Paume para observar de cerca la Vista de Delft de Vermeer, no por amor desinteresado a la pintura sino porque ese cuadro precisamente era el preferido de su novelista inventado, Bergotte, cuya muerte había contado ya (...). Proust sufrió un desvanecimiento delante de ese cuadro que era para él un emblema de la capacidad suprema del arte para apresar la belleza y el temblor de lo real y hacer duradero lo más fugitivo: esa mancha dorada del primer sol de la mañana en un muro de ladrillo.

O día 1 de maio, nesta mesma exposición, Castelao vaise deter noutro cadro de Vermeer Tête de jeune fille, do que apunta:

Johannes Vermeer(1632-1675) ten un cadro Tête de jeune fille que é unha marabilla; chea de luz branca a cara que xurde nun fondo de tebras, pódense contalas pinceladas, pinceladas tan xustas e de côr tan axeitado que podia ser o xenio que compre para ista sintesis de que tanto se fala. (Castelao 1977: 125-126).

Outro pintor admirado por el no Jeu de Paume é Van Gogh (actualmente a súa obra, da conservada en París, está no Museo d’Orsay) ${ }^{12}$ : «É un dos impresionistas que máis me gostan. Parecen cousas feitas con lápices de côres dando a mesma sensación de puntillismo» (Castelao 1977:124). Visitar o citado museo sería unha boa idea para contemplar a magnífica colección dos impresionistas (no 1921 estaban nas salas de: Jeu de Paume, Louvre, Luxemburgo e en exposicións temporais), en palabras súas: «Din que Corot, Daubigny, o estudo do arte xaponés e a influencia de Turner fixeron nacer o impresionismo. ¿Que máis dá? O que importa é que soamente me gostaron os impresionistas...» (1977:52).

Outras suxerencias del, coas que marabillarse nestas salas: Carrière, Degas, Renoir, Pissarro, Caillebotte... e o cadro Le pauvre pècheur de Puvis Chavanes do que di: «... e non sei como pode haber no mundo quen non sinta abalar o corazón diante dista obra» (1977:54). Tal como recolle no Diario dedicou bastante tempo ás exposicións dos impresionistas e ao estudo destas obras (Castelao 1977:52):

Claude Monet cos seus cadros que representan a Catedral de Rouen, (sempre a mesma catedral en dias, horas e luz diferentes) ben demostra o estudo feito por iste artista e o convencimento seu de poder conseguir máis efeutos descompondo as côres.

${ }^{11}$ No museo Carnavalet,dedicado á historia de París, está conservado o dormitorio deste célebre autor, onde escribiu a meirande parte da súa obra. Ligazón: https://www.carnavalet.paris. fr/es/museo-carnavalet.

12 Para contemplar as obras que se citan: https://m.musee-orsay.fr/es/inicio.html. 
Este cadro quizá fose o que o inspirou para escribir o fermoso discurso sobre Valle- Inclán, que pronuncia na Universidade da Habana, o 7 de xaneiro de 1939. A paisaxe arousá aparece descrita en distintas estacións e distintas horas do día, ao igual que a catedral de Rouen no cadro de Monet (Castelao 2000 a: 391-393):

Paisaje de una tarde de verano

Entre los sauces brilla una hoz de agua. Arden las cumbres del Barbanza y por la ría navega un patache.(...)

Paisaje de un anochecer

La tierra se acomoda para dormir (...) y en la plata bruñida de la ría se refleja un lucero.

Paisaje de una noche de luna (...) se adivina el Barbanza y la ría. La luna quedó colgada en la rama de un pino.

Paisaje de una mañana de fiesta

Ayer ha llovido y hoy luce el sol. El Barbanza es azul. La ría es un espejo. Los campos amarillean de flores.

Paisaje de un mediodía de lluvia

Los hilos de agua ocultan las lejanías. El humo se arrastra por los tejados brillantes. (...) Ayer naufragó una lancha.

Paisaje de una tarde de invierno

La ría es de plomo(...) huele a sal del Atlántico.

Despois de nos mergullarmos neste vasto océano de cores no museo d'Orsay, recollemos os nosos apuntamentos e seguimos, silandeiramente, os seus pasos. De volta ao seu Barrio Latino cruza as rúas orballadas e escuras e pide pardon ao chocar cunha señora enloitada, a cal, cavilosa, nin se decata da súa cortesía. Podería tratarse de Maria Sklodwska-Curie, porque o seu laboratorio, o Radium Institute (actual Museo Curie), estaba preto da súa vivenda. Sexa como for, o certo é que vive nun barrio que era un fervedoiro de teorías científicas as cales van influír decisivamente na nosa existencia e na concepción dunha Arte Nova. O descubrimento dos raios X amosan a ambigüidade das ideas do interior e exterior, o opaco faise transparente, a diferenza entre bidimensionalidade e a tridimensionalidade queda esvaída. As novas sobre a radioactividade parecen demostrar que o espazo está cheo de raios alfa, beta, gamma que o cruzan todo. Todas estas teorías se discutían nos cafés, tal como describe Bonet Correa (2012:101):

Los cafés de París, que van de Montmartre hasta Montparnasse, pasando por la rive gauche a Saint-Germain-des-Près, marcan el nacimiento de movimientos tan trascendentales para el mundo moderno como: la Ilustración y el Romanticismo, el Realismo y el Simbolismo, el Impresionismo, el Cubismo, el Surrealismo o el Existencialismo.

Malia todos estes descubrimentos que ían cambiar a concepción da nosa existencia, o mundo da ciencia tiña dificultades para financiar os seus estudos. Por iso o día 21 de abril, no teatro da Ópera, mentres Castelao visita a Exposition 
da Societé nationale des Beaux-Arts, esta prestixiosa científica vai recibir unha homenaxe do mundo da ciencia, entre o numeroso público, científicos destacados: Paul Langevin e Émile Borel. Uns días despois, Marie Sklodwska-Curie vai emprender unha viaxe a EEUU para recoller un gramo de radio de mans do presidente Harding. Resulta curioso que moitos anos despois, en Bos Aires, Castelao ilustre o libro: Marie Curie. Su vida y obra. Esta obra recolle, como ben indica o título, os fitos máis sobranceiros da súa vida e tamén moitas anécdotas da súa vida persoal, das súas investigacións e da súa docencia. Precisamente, un dos seus debuxos titúlase: Marie Curie comparece en la Casa Blanca, que alude á viaxe antes citada e outro: Marie Curie en el Barrio Latino, que retrata os duros comezos na súa vida en París. Son os camiños da vida e do tempo que se tecen máis aló das fronteiras dos nosos soños.

Agora, xa no noso cuarto, tentaremos resumir as súas notas e os libros que mercou nos bouquinistes e nas librarías. Fai importantes estudos sobre o cubismo que enviará á Revista Nós e para a Memoria da Xunta de Estudos. A teoría cubista parécelle moi interesante, como ben proban todas as anotacións que fai tanto na obra de A. Gleizes Du cubisme et des moyens de le comprendre coma nas de M. Raynal: Les maîtres du cubisme e Quelques intentions du cubisme. Nestes libros subliña as características desta escola: multiperspectivismo, xeometrización, síntese, fragmentación de volumes, desexo de crear unha nova realidade. Mais, aínda que lle interesa a doutrina, non lle gustan os cadros cubistas (Castelao 1977:74):

Estou estudiando cun folleto que merquei titulado Cubisme et tradition as intenciós dos artistas cubistas. Quero, denantes de sair de París, decatarme da razón das novas escolas. Anque unha cousa son as obras novas e outra a sua literatura; pois non atopéi ben realizado ningún dos propósitos do xoven arte.

Teorizou sobre esta corrente, pero non vai seguir esta escola. Porén, a profesora Silvia Manteiga Pousa no artigo: $O$ cubismo en un ollo de vidro destaca que a fragmentación da súa obra en distintos planos en: Cousas, Retrincos e Os dous de sempre coincide coa ruptura de estruturas propias do cubismo: «A súa fórmula narrativa, sen embargo, fundirá técnicas cubistas, no desdobramento de planos, mais cunha explosiva mistura de lirismo e de humor doente e dorido.» (1989: 163-171) Mais agora deixaremos as teorizacións cubistas e botaremos unha mirada nostálxica aos espectáculos teatrais dos anos vinte que tanto éxito tiñan daquela. No mes de abril acode a unha representación do teatro ruso Chauve-Souris na sala Fémina (1907-1929) nos Campos Elíseos. No programa de man desta función recóllese a esencia desta arte:

On y a conservé le culte de la stylisation, du jeu harmonieux des coleurs, de l'expresion concentrée, et l'on s'est efforcé d'y entretenir entre la scène et l'auditoire une intime communion de sensations et d'idées(...) 
Toutes les ressources de l'esthètique: parole, mimique, musique, peinture, danses ont été mises en ouvre à la Chauve- Souris et cette syntèse a toujours atteint la hauteur de l'art le plus pur $(\ldots)^{13}$

No seu Diario vai plasmar unha reflexión case idéntica á recollida nese programa (Castelao 1977: 106):

¿Qué decir diste teatro tan novo e tan orixinal? É a estilización de todo: parola, mímica, música, pintura, danzas. Son as grandes obras do pobo ou dos grandes artistas sintetizadas e cinceladas dispois coma xoias. Côr i expresión concentrada pra eispresar fortemente dun xeito sintético unha parodia, unha bufonada, unha sátira, unha ironía e aínda a "mise en scéne" de algunha obra literaria ou musical.

Resulta moi inspirador o contexto artístico tan efervescente do París dos anos vinte, onde aínda resoaban os ecos de Parade (1917), espectáculo rupturista, cuxas características resumiu Apollinaire no programa de man: «une alliance nouvelle, celle de la peinture et de la danse, de la plastique et de la mimique qui est le signe de l'avenement d'un art plus complet (...) une sorte de sur-realisme». Un termo, por certo, que utilizará André Bretón (1896-1966) para nomear a nova corrente artística, cuxas ideas difundirán na revista Littératture, matinada no hotel des Grands Hommes, entre os anos 1919-1924, na praza Panteón, moi cerca do hotel do noso viaxeiro, onde, dende o 1918 até 1920 , vive Bretón. Mais volvendo ao tema do teatro ruso, Castelao cavila, longamente, na idea de facer algo semellante en Galicia. De volta a Galicia asina un documento, achado no arquivo da Fundación Vicente Risco, titulado «Prouyeuto de teatro galego ao xeito do da Chauve Souris». Este proxecto, analizado por Tato Fontaína, nunca será levado a cabo por varias razóns (Tato Fontaíña 2019: 244):

Como sabedes ese proxecto non se realizou porque, ademais da imposibilidade de crear en Pontevedra dúas entidades artísticas, as medidas represoras da ditadura do xeneral Primo de Rivera (1923-1930) acabaron con todas as actividades escénicas que non estivesen ligadas ao folcklore, polo que desapareceron todos os grupos de teatro galego, abrindo unha paréntese na súa evolución.

O esquema que el trae de París para escribir a súa obra de teatro vai ser modificado polas circunstancias, tal como indica Tato Fontaína, e como sinala o autor na nota «Ao marxe da farsa" que precede a obra (Castelao 1999:455):

13 Pódese ver o programa completo desta función: La Chauve-Souris à Moscou de Nikita Balief au Théâtre Femina, avril 1921en: http//data.bnf.fr/fr/11717088/ compagnie_de_la_Chauve_Souris. (última consulta: 20/12/2020).

Tradución do francés: Conservouse o culto da estilización, do xogo harmonioso das cores, da expresión concentrada, e fíxose un esforzo por manter entre o escenario e o público una comuñón íntima de sentimientos e de ideas (...) Todos os recursos da estética:parola, mímica, música, pintura, danzas implementáronse na Chauve- Souris e esta síntese atinxiu sempre o nivel da arte máis pura. 
As feituras con que se presenta esta farsa non responden ao pulo que a iniciou porque, no decorrer de tanto tempo, esvaéronse os pormenores da súa primeira traza ao faltarlle unha continuidade de pensamento e emoción.

Na mesma liña, Manuel Vieites no seu artigo "Castelao, o movemento dramático nacional e o teatro nacional popular" sostén que a achega que, finalmente, fai ao teatro galego non responde á estética do Teatro da Arte que viu en París: «Os bosquexos de París están na liña dun teatro visual, renovador e paródico, mentres que a peza escrita entre Pontevedra e Nova York se sitúa no marco dun teatro popular.» (Vieites 2000:260) Dito o anterior, e proseguindo co intento de describir as vivencias parisienses presentes na súa obra, sinalamos os seguintes esbozos anotados no seu Diario que aparecen nos lances II e III de $O s$ vellos non deben de namorarse (Castelao 1977:107):

Os monicreques terán a cabeza de persoas e os corpos de trapo valdeiros e iso pódese faguer asomando somentes as cabezas e manexando cuns pauciños as manciñas dos monicreques (Lance III).

Unha parexa ou un grupo poden cantar calquera cousa axeitada; pero han sere os personaxes dun cadro pintado que non teña máis que as cabezas de verdade e tan ben pintadas que parezan brochazos (Lance III).

Tamén pode haber conversas antre os retratos dunha sala e sería de moito humor faguer intervir o personaxe dun cadro (...)que agora entérase das cochinadas que fan os descendentes dun cabaleiro que foi seu amo e antigo dono da casa. Deixo apuntadas isas cousas que se me ocurriron. Do noso folcklore sairán cousas a milleiros" (Lance II).

A escena cuarta (lance III) da mesma obra recrea o ambiente inspirado nunha visita moi particular que fai o 15 de marzo (Castelao 1977:84):

Hoxe estiven nunha chea de sitios pintorescos. Estiven na casa dun home que se di "osteologist"; é unha casa escura e miserabel. Na mesma porta óllase un letreiro no que un pode enterarse que no primeiro piso véndense hósos humáns soltos, caliveras, esqueletos, etc.

A atmosfera anteriormente descrita aparece tamén no relato de Ramón Carballo, en Cousas (Castelao 1999: 98-99):

Unha sala chea de ósos humáns, algúns aínda frescos, compoñía o comercio para médicos(...) Un dos coiros era do peito dun home, representando un paxaro cunha carta no peteiro e debaixo do deseño campaba iste nome: Ramón Carballo.

A escena de Cousas, «Si eu fose autor escribiría unha peza en dous lances», en principio, estaba concibida para crear un texto teatral (era un dos sketchs anotados no seu Proxecto de teatro galego) recrea unha anécdota recollida no seu Diario (Castelao 1977:149): 
Hoxe contoume un francés o disgusto dunha fidalga de París por morrérselle... un canciño. O francés refireume o sentimento da señorona con verdadeira emoción para demostrarme o bó curazón da señora. Eu lembreime de camiño dos contos que se contan do galego a quén se lle morre unha vaca e decateime do lonxe que está un sentimento do outro e a diferencia que hai antre un canciño mal criado e unha vaca que dá pra vivir(...) Amostrar istes dous sentimentos dá motivo pra un conto.

Outro dos relatos de Cousas titulado: «Vouvos contar un conto triste» está inspirado na visita ao Musée Dupuytren (museo de Medicina, creado no 1833, actualmente, pechado). A escena dos fetos nos tarros de formol que debuxa ao final do conto evoca as imaxes deste museo. En palabras do propio autor, nunha carta a Rodrigues Lapa, un dos protagonistas, Rañolas, da súa novela $O s$ Dous de Sempre é un personaxe real: «Cómpre decirlle que Pedro é unha invención miña; pero Rañolas eisisteu e fixo todo canto eu digo, incrusive foi real o suicidio- menos o de deixar aquel PROTESTO na parede, etc.» (Castelao 2000 b:246-247).

Rañolas deambula por París e, ao igual que a maioría da poboación francesa, afronta cada amencer coa angustia da supervivencia. O proletariado vive unha situación moi crítica. Por mor das duras negociacións que cumprían para conseguir apoios para a reconstrución do país, as dificultades políticas e económicas eran moitas. Heminway escribe París era una fiesta, mais o París da Belle Époque desapareceu como un escenario, ao baixar a cortina. Máis de un millón de inválidos permanentes (igual que o noso protagonista), máis de un millón de mortos, miseria, fame. Fronte a esta desolación existe outro París que vive no luxo, na festa e que goza cada noite os días gañados á destrución da atroz e longa Primeira Guerra Mundial. Os seus escenarios son os Grandes Bulevares e os Campos Elíseos onde campan os ricos norteamericanos. Comezaban os tolos anos 20 de fala anglosaxoa. Castelao manifesta o seu descontento fronte a este París frívolo e consumista: «Hoxe arrisqueime a ir ós boulevards e aquilo deume noxo» (Castelao 1977: 35), pola contra admira a arquitectura e a beleza da cidade: «Os edificios tan fermosos e tan ben situados, recortados no ceo gris teñen o aspeuto de estaren nevados» (1977:30).

O autor reconstruíu a existencia de Rañolas furgando nos seus recordos, recollendo memorias e nostalxias esvaecidas. Así os dous van comer ao restaurante L'Ami, un dos máis emblemáticos da cidade - na película Un americano en París (1951), dirixida por Vincenti Minnelli, os dous protagonistas desta teñen unha cita nese restaurante-. Autor e personaxe comparten o decorrer do tempo, a morriña e os cambios na paisaxe nos xardíns de Notre-Dame: «Rañolas ollou agoma-los albres no xardín de Notre-Dame, saudoso da primaveira dos campos» (Castelao 1999:323). No Diario: «jAi, aquiles gomos verdes e aquiles botóns de ouro que nascen nas leiras!» (Castelao 1977: 90).

Camiñan polas rúas, ás veces seguros de si mesmos, outras veces cavilosos polo medo á fame e á enfermidade: «Rañolas estaba enfraquecido de tanto xaxún e xa lle regañaban os cóbados» (Castelao 1999:324). No Diario: «notei que estou enflaquecendo moito e teño medo, un medo que me asombra...» 
(Castelao 1977:149). Os dous cavilan na futilidade e asfixiante vida cotiá da grande cidade: «ten unha lembranza para os paxaros bonitos que saben cantar e que prefiren a morte a seren mendicantes de cibdade» (Castelao 1999:323).

No Diario: «Eu non viviría en París, non por sere París senon por sere unha grande cibdade» (Castelao 1977: 46). Nas primeiras páxinas do Diario, reflexiona sobre a diferenza do ritmo temporal entre a cidade de París e o ritmo cósmico máis presente na nosa Terra, iso lévao a dicir: «Teño a manía de non mercar un reló (...). Como estou soio i eiquí todo se fai a horas fixas pensei mercar un, e ¡ou bondade! acabo de escoitar as once da noite nun reló veciño.» (1977: 30) E así, deste xeito, Rañolas convértese en reloxeiro, quizais, o que lle vendeu o reloxo ao noso escritor e o inspirou para construír este personaxe.

Pechamos o caderno e a fiestra; a noite vai pousando as súas sombras. Mañá emularemos ao noso viaxeiro e iremos á Biblioteca Nacional Richelieu. Se a climatoloxía nolo permite, pasaremos polos xardíns do Palais Royal onde baixo o berro: Ás armas, cidadáns! no aristócrata Café de Foy, paradoxicamente, en xullo de 1789, deu comezo a Revolución Francesa. Se chover, agocharémonos na galería Vivienne, onde o tempo, detido nas sombrerarías, teterías e librarías de vello, parece evocar as teorías da Ilustración: liberté, egalité, solidarité xurdidas na veciña rúa Deschamps, no pazo do barón Holbach, onde se reunían Diderot, Rousseau e outros. Xa na biblioteca pasaremos á sala de lectura Labrouste, unha das obras máis belas do século XIX. Pediremos os debuxos de Callot (1592-1635) para ver os seus gravados: Les Grandes Misères et Malheurs de la Guerre inspiradas nos sucesos da Guerra dos Trinta Anos e compararemos con Os Álbums de Guerra do noso artista.

Mentres os pardais nos observan inquisitivos, sabedores da nosa angustia por non podermos voar; despediremos ao noso artista, cunha ollada de vertixe dende a Tour Eiffel; cavilando na identificación que fai desde o alto da torre, entre o traballo dos homes nunha grande cidade co traballo das formigas ou das abellas: «Aquil esforzo de tantos miles de homes non é o que máis nos asemella ós homes: é un traballo de formigas ou de abellas que por instinto fan un formigueiro ou unha colmea» (Castelao 1977:171). Monumento emblemático da cidade. Para algúns, desastre arquitectónico; para outros, marabillosa obra de arte: Guitare du ciel, ta télégraphie sans fil attire les mots comme un rosier les abeilles, recitaba Vicente Huidobro, fundador do creacionismo, versos que parafraseou Risco na súa obra Mitteleuropa (1931).

\section{III.- CONCLUSIÓNS}

Existe, actualmente, unha necesidade de poñer en valor o Diario de 1921 esta magna obra ten moito, aínda, que nos dicir. Testemuño dos movementos estéticos máis importantes da Europa dos anos vinte, ao longo das súas páxinas desfilan innumerábeis datos, precisas descricións, bosquexos e, en ocasións, debuxos e reflexións, todo isto mesturado con certa ironía e os trazos de humor tan de seu do noso artista. 
Sosego, reflexión, lecturas, estudo e un degoiro: crear unha Arte galega. Polos avatares que sofre despois, quizais nunca volva a ter tanto tempo de tranquilidade para traballar e darlle ao maxín. De aí que as cavilacións e ideas, ás veces, tan só enfiadas, que vai recollendo nestes meses agromen tanto na súa obra pictórica coma literaria. Sen a melancolía que sentiu Castelao nestes meses fóra de Galiza non tería concibido nin a Rañolas nin a Pedro. Sen os apuntamentos das exposicións que contempla en París, a súa arte teceríase con outros fíos, sublimes, seguramente, mais doutro xeito. Neste traballo, pois, intentamos recompilar algunhas analoxías, xa descritas, e outras novas para subliñar o vínculo con esta cidade. Somos conscientes de que só son unhas cantas ideas, mais sexa como for, quizais dean lugar a outras olladas sobre a súa obra. O camiño fica, con todo, iniciado.

Seguindo as súas camiñadas fomos transitando polas rúas parisienses en precario equilibrio na procura da beleza e da arte. E, se callar, non quixésemos viaxar coas rutas marcadas, percorreremos a cidade ao chou, apañando cada momento no ar, vendo sen ser vistos, gozando de elixir morada no movemento, no fuxitivo, no infinito coma o Rañolas. E sentiremos que todo París é de noso.

\section{BIBLIOGRAFÍA}

Asaka, Takekazu (2015) En torno á cuberta de Vento Mareiro de Ramón Cabanillas. Toquio (inédito).

Bonet Correa, A. (2012) Los cafés históricos. Madrid, Catédra.

Camus, A. (2006) El revés y el derecho, Madrid, Alianza Editorial.

Castelao, A.D (1977) Castelao Diario 1921. Francia, Bélxica, Alemaña, Vigo, Galaxia.

Castelao, A.D (1995) Galicia mártir. Atila en Galicia. Milicianos. Estampas por Castelao, Vigo, Edicións A Nosa Terra.

Castelao, A.D (1999) Edición da obra literaria de Castelao. Tomo1, Vigo, Galaxia.

Castelao, A.D. (2000a) Palestras de arte. Discursos parlamentares e políticos. Conferencias na Universidade da Habana. Apéndices, Tomo 4, Vigo, Galaxia.

Castelao, A.D.(2000b) Epistolario, Tomo 6, Vigo, Galaxia.

Dirks, R. (1909) Augusto Rodin. Madrid, Saenz de Jubera, Hnos(Imprenta Alemana).

Emanuel,Francis L. (1909) Los dibujantes de Montmartre, Madrid, Saenz de Jubera.Hnos.(Imprenta Alemana, rúst. Grab. Intercal.).

Espinar Jaime (1945) Marie Curie, su vida y obra. Ilustraciones de Castelao, Buenos Aires, Editorial Atlantida. 
Fernández Rei, F. (2015)"Cabanillas, Cambados e o Vento mareiro" in Boletín da Real Academia Galega, $\mathrm{n}^{\circ}$ 376. A Coruña, Fundación Barrié/ Real Academia Galega. http://publicacionsperiodicas.academia.gal/index.php/ BRAG/article/view/491/505. [Última consulta: 12/02/ 2021].

Feuchtwanger, Lion (1966) Obras selectas. Novelas: Lion Feuchtwanger,la persona y la obra; El judio Süss; Goya o el duro camino de la comprensión; Exilio. Barcelona, Editorial Planeta.

Filgueira Valverde, X.(1977) "Limiar, sipnosis, e rexistro de artistas" en Castelao, Diario 1921 Francia, Bélxica, Alemaña, Vigo, Galaxia.

Gleizes, Albert(1921) Du cubisme et des moyens de le comprendre, París, Editions La Cible Union.

Hemingway, E.(1994) París era una fiesta, Barcelona, Círculo de Lectores.

Huidobro, V. e Delaunay, R. (1918) Tour Eiffel, Madrid.

Manteiga, Silvia (1989) "O cubismo en un ollo de vidro", Congreso Castelao:24-29 novembro, Servizo de Publicacións da Universidade de Santiago de Compostela.

Muñoz Molina, C.A. (2013) "La fiebre manuscrita", El País. Dispoñible en Internet: (http: www.elpais.com/autor/antonio.munozmolina) [Última consulta 18/1/2021].

Otero Pedrayo, R.(1926) Arredor de si. Vigo, Galaxia.

Otero Pedrayo, R. (1975) "Homenaxe a Castelao", en Grial, 47,Vigo, Galaxia.

Raynal, M.(1920a) Les maîtres du Cubisme. París, Editions de L’Effort, Leonce Rosemberg.

Raynal, M.(1920b) Quelques intentions du cubisme, París, Editions de L’Effort, Leonce Rosemberg.

Risco, V.(1934) Mitteleuropa, Vigo, Galaxia.

Steinlen,T. (1918) "La guerre par Steinlen" en L'art et les artistes. París. Numéro spécial, Revue des deux mondes.

Tato Fontaíña, Laura. (2019): "Os vellos non deben de namorarse, de Castelao: xestación e recepción", en Madrygal. Revista de Estudios Gallegos. Dispoñible en Internet: https://doi.org/10.5209/madr.66862. Tamén en: http:// hdl.handle.net/2183/24793.

Vieites M. F. (2000) "Castelao, o movemento dramático nacional”, Para ler a Castelao. Estudios sobre a súa escrita, Tomo 2. Vigo, Galaxia. 